\title{
Inhibitory Effect of $t$-Butyl Hydroperoxide on Mitochondrial Oxidative Phosphorylation in Isolated Rat Hepatocytes
}

\author{
P. KŘIVÁKOVÁ ${ }^{1}$, A. LÁBAJOVÁ ${ }^{2}$, Z. ČERVINKOVÁ ${ }^{1}, Z^{\text {Z }}$ DRAHOTA ${ }^{1,3}$ \\ ${ }^{1}$ Department of Physiology, Faculty of Medicine, Charles University, Hradec Králové, ${ }^{2}$ Institute of \\ Pathophysiology, First Faculty of Medicine, Charles University, Prague, ${ }^{3}$ Center for Molecular \\ Genomics, Institute of Physiology, Academy of Sciences of the Czech Republic, Prague, Czech \\ Republic
}

Received April 18, 2006

Accepted October 6, 2006

\begin{abstract}
Summary
Using high-resolution oxygraphy, we tested the changes of various parameters characterizing the mitochondrial energy provision system that were induced by peroxidative damage. In the presence of succinate as respiratory substrate, $3 \mathrm{mM}$ $t$-butyl hydroperoxide increased respiration in the absence of ADP, which indicated partial uncoupling of oxidative phosphorylation. Low activity of coupled respiration was still maintained as indicated by the ADP-activated and oligomycin-inhibited respiration. However, during the incubation the phosphorylative capacity decreased as indicated by the continuous decrease of the mitochondrial membrane potential. Under these experimental conditions the maximum capacity of the succinate oxidase system was inhibited by $50 \%$ in comparison with values obtained in the absence of $t$-butyl hydroperoxide. Our data thus indicate that the oxygraphic evaluation of mitochondrial function represents a useful tool for evaluation of changes participating in peroxidative damage of cell energy metabolism.
\end{abstract}

\section{Key words}

Hepatocytes • Oxidative phosphorylation $\bullet t$-Butyl hydroperoxide

$t$-Butyl hydroperoxide ( $t$-BHP) is widely used as a prooxidant in studies evaluating the sensitivity of various cell enzymes and cell membrane structures to oxidative damage (Kennedy et al. 1992, Nieminen et al. 1997, Leal et al. 1998, Kmoníčková et al. 2001). In our previous paper, we have found that mitochondrial enzyme complexes of the respiratory chain have a different sensitivity to $t$-BHP action. Complex I was more sensitive than complex II (Drahota et al. 2005). Critical concentration of $t$-BHP for Complex I inhibition was
0.75-1.5 mM, whereas succinate oxidation could be detected even at $3 \mathrm{mM}$ t-BHP. In this communication, we have extended our previous findings and used succinate as the respiratory substrate and studied in more detail the effect of $t$-BHP on various reactions of the mitochondrial system of oxidative phosphorylation. Using a highresolution oxygraphy technique we measured steady-state respiration as well as respiration activated by ADP, inhibited by oligomycin or activated by the uncoupler carbonylcyanide p-trifluoromethoxyphenylhydrazone 

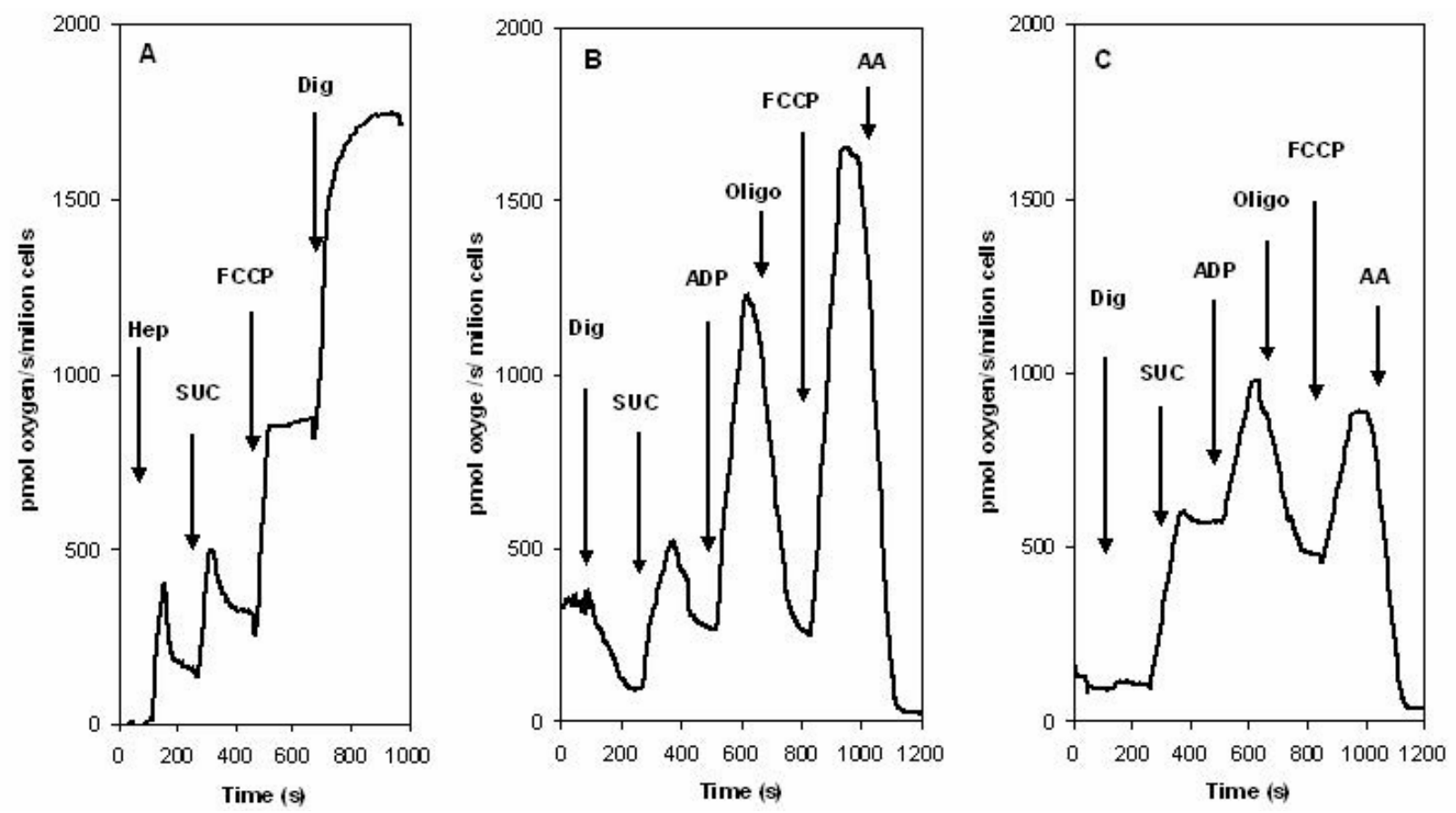

Fig. 1. A: Activation of FCCP-stimulated succinate oxidation by digitonin. Hepatocytes were incubated in the $\mathrm{KCl}$ medium as described above. Where indicated, hepatocytes (Hep, 0.5 million/ml), succinate (SUC, $10 \mathrm{mM})$, FCCP $(1 \mu \mathrm{M})$ and digitonin (Dig, $0.02 \mathrm{mg} / \mathrm{ml})$ were added. The same results were obtained with three different preparations of hepatocytes. B: Control hepatocytes $(0.5 \mathrm{million} / \mathrm{ml})$ in $\mathrm{KCl}$ medium containing $2 \mu \mathrm{M}$ rotenone. Where indicated digitonin (Dig, $0.02 \mathrm{mg} / \mathrm{ml}$ ), succinate (SUC, $10 \mathrm{mM})$, ADP (1.5 mM), oligomycin (Oligo, $2 \mu \mathrm{M})$, FCCP $(1 \mu \mathrm{M})$ and antimycin A (AA, $1 \mu \mathrm{M})$ were added. C: Hepatocytes $(0.5 \mathrm{million} / \mathrm{ml})$ were preincubated for 10 min with $3 \mathrm{mM} \mathrm{t}$-BHP before permeabilization by digitonin (Dig, $0.02 \mathrm{mg} / \mathrm{ml}$ ). Other additions were the same as in Fig. $1 \mathrm{~B}$.

Table 1. The effect of $t$-BHP on succinate-dependent respiration and ADP phosphorylation in isolated hepatocytes.

\begin{tabular}{lllc}
\hline & Control & $\mathbf{+ 3} \mathbf{~ m M ~} \boldsymbol{t}$-BHP & $\boldsymbol{t}$-BHP/Control \\
\hline Hep + Rot + Dig & $130.3 \pm 4.1$ & $121.1 \pm 5.1$ & 0.93 \\
+ Succinate & $385.7 \pm 16.1$ & $677.1 \pm 25.7$ & 1.78 \\
+ ADP & $1203.1 \pm 47.6$ & $1066.1 \pm 38.9$ & 0.89 \\
+ Oligo & $282.1 \pm 18.7$ & $552.1 \pm 21.9$ & 1.85 \\
+ FCCP & $1469.7 \pm 36.1$ & $918.3 \pm 35.7$ & 0.62 \\
+ AA & $20.3 \pm 2.4$ & $35.7 \pm 5.5$ & 1.60 \\
$R C I(1):(+A D P /$ ADP $)$ & $3.12 \pm 0.04$ & $1.58 \pm 0.06$ & 0.50 \\
$R C I(2):(+A D P /+$ Oligo $)$ & $4.31 \pm 0.38$ & $1.93 \pm 0.05$ & 0.45 \\
$R C I(3):(+F C C P /+$ Oligo $)$ & $5.31 \pm 0.48$ & $1.68 \pm 0.14$ & 0.32 \\
\hline
\end{tabular}

Hepatocytes ( Hep, 0.5 million/ml) were incubated in $2 \mathrm{ml}$ of the $\mathrm{KCl}$ medium at $30{ }^{\circ} \mathrm{C}$. Rotenone (Rot) was $2 \mu \mathrm{M}$, digitonin (Dig) $20 \mu \mathrm{g} / \mathrm{ml}$, succinate $10 \mathrm{mM}$, ADP $1 \mathrm{mM}$, oligomycin (Oligo) $3 \mu \mathrm{M}$, FCCP $2 \mu \mathrm{M}$, antimycin A (AA) $2 \mu \mathrm{M}$. Respiratory control index (RCI) was calculated under different conditions as RCI $(1,2,3)$. The values (in pmole oxygen/s/million of cells) represent average \pm S.E.M. from 4 preparations of hepatocytes.

(FCCP). From these data we calculated steady-state and maximum rates of succinate oxidation and the respiratory-control index $(\mathrm{RCI})$ indicative of integrity of mitochondrial membranes. We measured also oligomycin sensitivity of ADP-stimulated respiration, which indicated the function of the ATP-synthase complex.

We used rat hepatocytes isolated from adult male Wistar rats (220-240 g) as described in our previous paper (Drahota et al. 2005). The advantage of this experimental model is that we can apply $t$-BHP to intact cells. After their permeabilization with digitonin, we can evaluate mitochondrial function under the conditions that are closer to the in situ conditions compared to isolated mitochondria (Wenchich et al. 2003). Moreover, the 
mitochondrial membranes remain intact (Vercesi et al. 1991) and their interaction with the cytoskeleton network is preserved (Fiskum et al. 1980, Garesse and Vallejo 2001). It might be important especially for diagnostics and toxicology studies to measure the activity of mitochondria under the conditions that are close to the physiological situation.

Oxygen consumption was measured by the high resolution oxygraph OROBOROS (Austria) at $30{ }^{\circ} \mathrm{C}$ in a medium containing $100 \mathrm{mM} \mathrm{KCl}, 10 \mathrm{mM}$ Tris- $\mathrm{HCl}$, $4 \mathrm{mM}$ K-phosphate, $3 \mathrm{mM} \mathrm{MgCl}_{2}, 1 \mathrm{mM}$ EDTA, (pH 7.4). Oxygen consumption was expressed as pmole oxygen per second per million cells. Oxygraphic curves indicate the rates of oxygen uptake, i.e. the first negative derivation of the oxygen concentration changes. For calculation and presentation of data OROBOROS software Datlab 3.1.1 was used. Mitochondrial membrane potential was measured as tetraphenylphosphonium $\left(\mathrm{TPP}^{+}\right)$concentration changes using computerized device with $\mathrm{TPP}^{+}$-selective electrode as described before (Lábajová et al. 2006). Incubation conditions were the same as for oxygen consumption measurements.

Figure 1A shows that added substrate and FCCP could not fully activate respiration of non-permeabilized cells, because addition of digitonin highly increased respiration with succinate and FCCP. Figure 1B shows the respiratory rates of control hepatocytes while Figure $1 \mathrm{C}$ shows the rates measured in hepatocytes preincubated for $10 \mathrm{~min}$ with $3 \mathrm{mM}$ t-BHP. In these experiments we used succinate as the respiratory substrate and $3 \mathrm{mM}$ $t$-BHP because our previous findings indicated that $1.5 \mathrm{mM} t$-BHP inhibited respiration of succinate and ADP only by $10 \%$ (Drahota et al. 2005). It is evident that $3 \mathrm{mM} t$-BHP affected many parameters characterizing the mitochondrial oxidative phosphorylation. Values of oxygen uptake calculated from the oxygraphic curves are summarized in Table 1. From these data we may conclude that $3 \mathrm{mM} t$-BHP has uncoupling effect as indicated by an increase of respiration in the absence of ADP and decrease of respiratory control index (RCI). The lower inhibitory effect of oligomycin on ADP-stimulated respiration confirmed that a smaller portion of oxygen uptake is associated with ATP synthesis. The maximum rate of succinate oxidation in the presence of uncoupler was reduced by $3 \mathrm{mM} t$-BHP to $60 \%$ of its original activity. Our data further revealed that at this high $t$-BHP concentration, when already lipoperoxidation of cell membrane appears (Kmoníčková et al. 2001), at least $50 \%$ of succinate-dependent respiration is still active as well as part of mitochondrial phosphorylating capacity, in contrast to the oxidation of NADH-dependent substrates (Drahota et al. 2005). However, a continuous decrease of mitochondrial membrane potential during the incubation of hepatocytes in the presence of higher dose of t-BHP $(3 \mathrm{mM})$ indicates a reduction of the respiratory chain capacity to maintain high proton gradient required for ATP synthesis (Fig. 2).

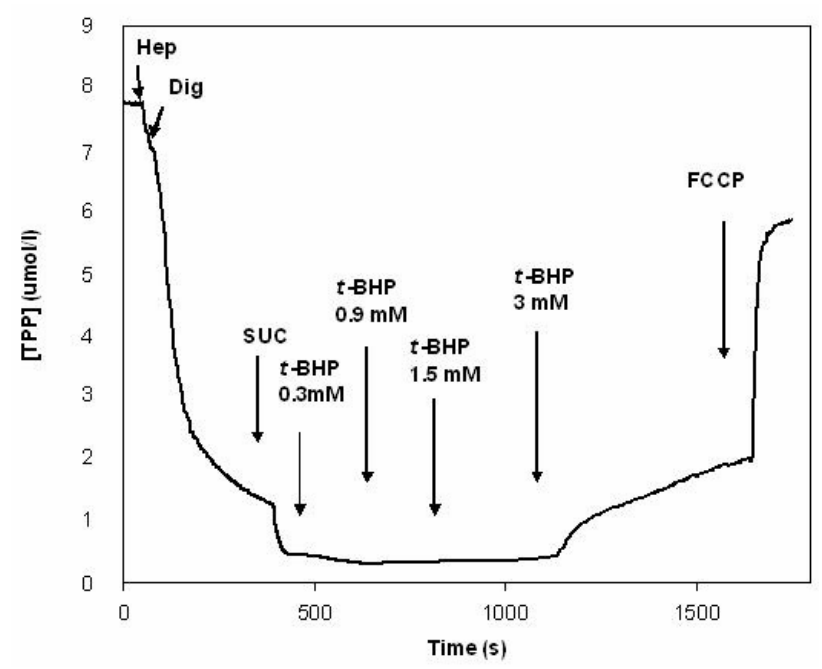

Fig. 2. Dissipation of mitochondrial membrane potential by $t$-BHP. Hepatocytes (Hep, $1.8 \mathrm{million} / \mathrm{ml}$ ) were incubated in the $\mathrm{KCl}$ medium as described above. Where indicated digitonin (Dig, $0.02 \mathrm{mg} / \mathrm{ml}$ ), succinate (SUC, $10 \mathrm{mM}$ ), t-BHP (sequential additions of $0.3+0.6+0.6+1.5 \mathrm{mM}$ to final concentration 3 $\mathrm{mM})$ and FCCP $(1 \mu \mathrm{M})$ were added. The same results were obtained with three different preparations of hepatocytes.

The effect of $t$-BHP on cell energy metabolism is a very complex process depending on its concentration and time of its action. Data in the literature showed that at low concentrations or in the first period of its action pyridine nucleotides, SH groups (Belomodo et al. 1984) and iron-sulfur clusters of various enzymes (Powell and Jackson 2003) are targets of its action. At these low concentrations the release of $\mathrm{Ca}^{2+}$ from intracellular stores was also detected (Belomodo et al. 1984, Kmoníčková et al. 2001). At higher $t$-BHP concentrations thiobarbituric acid-reactive substances are formed, indicating peroxidation of membrane lipids and destruction of cell membranes (Broekemeier et al. 1992, Kmoníčková et al. 2001). However, our data showed that at the high $t$-BHP concentration used $(3 \mathrm{mM})$, when already lipoperoxidation of cell membrane appears, at least $50 \%$ of succinate-dependent respiration is still active as well as a part of mitochondrial phosphorylating capacity. This 
could evidently be a very important factor for the initiation of regenerative processes after peroxidative damage of the liver.

\section{Acknowledgements}

This study was supported in part by grants from the Grant Agency of the Czech Republic (303/03/H065, 303/06/ 1261), Grant Agency of the Charles University (GAUK 126/04/C), AVOZ 50110509 and MSMT 11100008.

\section{References}

BELOMODO G, MARTINO A, RICHELMI P, MOORE GA, JEWELL SA, ORRENIUS S: Pyridine nucleotide oxidation, $\mathrm{Ca}^{2+}$ cycling and membrane damage during tert-butylhydroperoxide metabolism by rat mitochondria. Eur J Biochem 140: 1-8, 1984.

BROEKEMEIER KM, CARPENTER-DEYO L, REED DJ, PFEIFFER DR: Cyclosporin A protects hepatocytes subjected to high $\mathrm{Ca}^{2+}$ and oxidative stress. FEBS Lett 304: 192-197, 1992.

DRAHOTA Z, KŘIVÁKOVÁ P, ČERVINKOVÁ Z, KMONÍČKOVÁ E, LOTKOVÁ H, KUČERA O, HOUŠTĚK J: Tert-butyl hydroperoxide selectively inhibits mitochondrial enzymes in isolated rat hepatocytes. Physiol Res 54: 67-72, 2005.

FISKUM G, CRAIG SW, DECKER GL, LEHNINGER AL: The cytoskeleton of digitonine-treated rat hepatocytes. Proc Natl Acad Sci USA 77: 3430-3434, 1980.

KENNEDY C H, CHURCH DF, WINSTON GW, PRYOR WA: Tert-butyl hydroperoxide-induced radical production in rat liver mitochondria. Free Radic Biol Med 12: 381-387, 1992.

KMONÍČKOVÁ E, DRAHOTA Z, KAMENÍKOVÁ L, ČERVINKOVÁ Z, MAŠEK K, FARGHALI H: Modulatory effect on cyclosporin A on tert-butyl hydroperoxide-induced oxidative damage in hepatocytes. Immunopharmacol Immunotoxicol 23: 43-54, 2001.

LÁBAJOVÁ A, VOJTÍŠKOVÁ A, KŘIVÁKOVÁ P, KOFRÁNEK J, DRAHOTA Z, HOUŠTĚK J: Evaluation of mitochondrial membrane potential using computerized device with a $\mathrm{TPP}^{+}$-selective electrode. Anal Biochem 353: 37-42, 2006.

LEAL A M, RUIZ-LARELA B, MARTÍNEZ R, LACORT M: Cytoprotective action of estrogens against tert-butyl hydroxyperoxide-induced toxicity in hepatocytes. Biochem Pharmacol 56: 1463-1469, 1998.

NIEMINEN A-L, BYRNE AM, HERMAN B, LEMASTERS JJ: Mitochondrial permeability transition in hepatocytes induced by t-BuOOH: NAD(P)H and reactive oxygen species. Am J Physiol 272: C1286-C1294, 1997.

POWELL CS, JACKSON RM: Mitochondrial complex I, aconitase and succinate dehydrogenase during hypoxiareoxidation: modulation of enzyme activities by MnSOD. Am J Physiol 285: L189-L198, 2003.

GARESSE R, VALLEJO CG: Animal mitochondrial biogenesis and function: a regulatory cross-talk between two genomes. Gene 263: 1-16, 2001.

VERCESI H, BERNARDES CF, HOFFMANN ME, GADELHA FR, DECAMPO R: Digitonin permeabilization does not affect mitochondrial function and allows the determination of the mitochondrial membrane potential of Trypanozoma cruzi in situ. J Biol Chem 226: 14431-14434, 1991.

WENCHICH L, DRAHOTA Z, HONZÍK T, HANSÍKOVÁ H, TESAŘOVÁ M, ZEMAN J, HOUŠTĚK J: Polarographic evaluation of mitochondrial enzymes activity in isolated mitochondria and in permeabilized human muscle cells with inherited mitochondrial defects. Physiol Res 52: 781-788, 2003.

\section{Reprint requests}

P. Křiváková, Department of Physiology, Faculty of Medicine, Charles University, Šimkova 870, 50001 Hradec Králové, Czech Republic. E-mail:krivakovap@1fhk.cuni.cz 